\title{
Quick reference guide to apixaban
}

This article was published in the following Dove Press journal:

Vascular Health and Risk Management

10 July 2017

Number of times this article has been viewed

\section{Katherine Victoria Hurst John Matthew O'Callaghan Ashok Handa}

Nuffield Department of Surgical Sciences, University of Oxford, Oxford, UK
Correspondence: Ashok Handa Nuffield Department of Surgical Sciences, John Radcliffe Hospital, Headley Way,

Oxford OX3 9DU, UK

Tel +44 I865220302

Fax +44I865 768876

Email ashok.handa@nds.ox.ac.uk

\begin{abstract}
Direct oral anticoagulants (DOACs) are being increasingly used in the clinical setting for patients at risk of venous thromboembolism (VTE) and/or stroke. These medications offer valued benefits for long-term use, including a fast onset of anticoagulation, fixed anticoagulation profile (and consequent prescription of specified doses) and no requirement for routine monitoring. Apixaban is a selective factor Xa inhibitor, approved for use in the prevention of stroke in patients with nonvalvular atrial fibrillation and in the prevention and treatment of acute VTE. Like many of the DOACs, it has a fast onset of action and works to deliver predictable coagulation results. Multiple randomized controlled trials including ARISTOTLE and AMPLIFY have shown apixaban to be noninferior to vitamin $\mathrm{K}$ antagonists in the prevention of stroke and VTE, with a good safety profile. This article aims to review the use of apixaban for the prevention and treatment of thromboembolic disease, highlighting the key study results that have led to its current licensing and use.
\end{abstract}

Keywords: apixaban, stroke management, venous thromboembolism

\section{History and development}

In an era of anticoagulation development, more options mean more uncertainty. It is imperative for physicians and surgeons to be aware of the available anticoagulation medication, their licenses, dosing and indications. Familiarity with the systemic effects, bleeding risks and reversal options during the pre-, peri- and postoperative periods is of particular importance to surgeons.

Vitamin K antagonists (VKAs) have long been the preferred choice of anticoagulation, but their unpredictable effects, delayed onset of action and need for routine monitoring make them a challenging medication for clinical practice. The advent of the direct oral anticoagulants (DOACs) has revolutionized patient care, supported by multiple randomized controlled trials (RCTs) and meta-analyses prior to the introduction of routine clinical practice. ${ }^{1-3}$

To date, apixaban, dabigatran, edoxaban and rivaroxaban have gained therapeutic licenses within the UK and USA, and these have been secured on the basis of the RCTs listed in Table 1.

\section{Pharmacokinetics}

Apixaban is an oral factor Xa inhibitor that reversibly and selectively inhibits free and clot bound factor $\mathrm{Xa}$. It has a rapid onset of action, with peak effects at around 1-2 hours post dose, and a half-life of $\sim 12$ hours. With predictable pharmacokinetics, apixaban can be administered as a fixed twice daily (BD) regimen, without the need for 
Table I DOAC licenses and associated randomized controlled trials

\begin{tabular}{|c|c|c|}
\hline DOAC & Randomized controlled trial & Licensing \\
\hline \multirow[t]{3}{*}{ Rivaroxaban } & $\begin{array}{l}\text { EINSTEIN DVT (rivaroxaban vs } \\
\text { enoxaparin for DVT) }\end{array}$ & $\begin{array}{l}\text { Prevention of VTE in elective hip/knee surgery ( } 10 \mathrm{mg} \text { OD for } 35 / 12 \text { days, } \\
\text { respectively) }\end{array}$ \\
\hline & $\begin{array}{l}\text { EINSTEIN PE (rivaroxaban vs } \\
\text { enoxaparin for PE) }\end{array}$ & $\begin{array}{l}\text { Treatment of DVT and PE and prophylaxis after recurrent DVT/PE (I5 mg BD } \\
\text { for } 21 \text { days, then } 20 \mathrm{mg} O D \text { ) }\end{array}$ \\
\hline & $\begin{array}{l}\text { ROCKET AF (rivaroxaban vs } \\
\text { warfarin for AF) }\end{array}$ & $\begin{array}{l}\text { Stroke prevention in patients with } \mathrm{AF}+\text { one } \mathrm{CHADS}_{2} \text { risk factor }(20 \mathrm{mg} \mathrm{OD}) \\
\text { Prevention of atherothrombotic events in adults after acute coronary } \\
\text { syndrome ( } 2.5 \mathrm{mg} \text { OD) }\end{array}$ \\
\hline \multirow[t]{3}{*}{ Dabigatran } & $\begin{array}{l}\text { RE-COVER (dabigatran vs } \\
\text { warfarin for VTE) }\end{array}$ & $\begin{array}{l}\text { Treatment of DVT or PE after parenteral anticoagulation for 5-10 days ( } 150 \\
\mathrm{mg} \mathrm{BD)}\end{array}$ \\
\hline & RE-LY (dabigatran vs warfarin in AF) ${ }^{2}$ & $\begin{array}{l}\text { Stroke prevention in patients with } \mathrm{AF}+\text { one of reduced ejection fraction/CHD/ } \\
\text { diabetes } /<65(150 \mathrm{mg} \mathrm{BD})\end{array}$ \\
\hline & & $\begin{array}{l}\text { Prevention of VTE in elective hip/knee surgery ( } 110 \mathrm{mg} \mathrm{I-4} \mathrm{hours} \\
\text { after surgery, then } 220 \mathrm{mg} \text { OD 9/7) }\end{array}$ \\
\hline \multirow[t]{5}{*}{ Apixaban } & ARISTOTLE (apixaban vs & Stroke prevention in patients with $\mathrm{AF}+$ one $\mathrm{CHADS}_{2}$ risk factor $(5 \mathrm{mg} \mathrm{BD})$ \\
\hline & warfarin in $\mathrm{AF})^{5}$ & Prevention of VTE in elective hip/knee surgery ( $2.5 \mathrm{mg}$ BD for $35 / 12$ days, \\
\hline & AMPLIFY (apixaban vs enoxaparin & respectively) \\
\hline & followed by warfarin for VTE) ${ }^{4}$ & $\begin{array}{l}\text { Treatment of DVT and PE ( } 10 \mathrm{mg} \mathrm{BD} \text { for } 7 \text { days, then } 5 \mathrm{mg} \mathrm{BD}) \text {, or prophylaxis } \\
\text { after recurrent DVT/PE ( } 2.5 \mathrm{mg} \mathrm{BD})\end{array}$ \\
\hline & & Prevention of VTE (2.5 mg BD) \\
\hline \multirow[t]{2}{*}{ Edoxaban } & $\begin{array}{l}\text { ENGAGE-AF-TIMI (edoxaban } \\
\text { to warfarin in AF) }\end{array}$ & $\begin{array}{l}\text { Treatment of DVT or PE and prophylaxis after recurrent DVT/PE } \\
(60 \mathrm{mg} \text { OD) }\end{array}$ \\
\hline & $\begin{array}{l}\text { Hokusai VTE (edoxaban to } \\
\text { warfarin VTE) }\end{array}$ & $\begin{array}{l}\text { Prevention of stroke and systemic embolic events in patients } \\
\text { with AF ( } 60 \mathrm{mg} \text { OD) }\end{array}$ \\
\hline
\end{tabular}

Note: Bold indicates NICE license without US Food and Drug Administration license.

Abbreviations: AF, atrial fibrillation; $\mathrm{BD}$, twice daily; $\mathrm{CHADS}_{2}$, congestive heart failure, hypertension, age=75 years, diabetes mellitus, stroke (doubled); $\mathrm{CHD}$, coronary heart disease; DOAC, direct oral anticoagulants; DVT, deep vein thrombosis; NICE, National Institute for Clinical Excellence; OD, once daily; PE, pulmonary embolism; VTE, venous thromboembolism.

routine monitoring (Table 2$).{ }^{4}$ Currently available preparations include Eliquis ${ }^{\circledR}$ (Bristol-Myers Squibb Pharmaceuticals Ltd).

Its current licenses include ${ }^{4,5}$

- Prevention of stroke in patients with atrial fibrillation $(\mathrm{AF})+$ one congestive heart failure, hypertension, age $>75$ years, diabetes mellitus, stroke (CHADS) risk factor (5 mg BD).

- Prevention of venous thromboembolism (VTE) in elective hip/knee surgery (2.5 mg BD for 35/12 days, respectively).

- Treatment of deep vein thrombosis (DVT) and pulmonary embolism (PE) (10 mg BD for 7 days then $5 \mathrm{mg} \mathrm{BD}$ ).

- Prophylaxis after recurrent DVT/PE (2.5 mg BD).

Apixaban is eliminated in both urine and feces, with renal excretion accounting for $\sim 27 \%$. Consequently, it does not require renal dosing adjustments until the glomerular filtration rate falls below $30 \mathrm{~mL} / \mathrm{min}$. In such cases, a half dose $(50 \%)$ reduction is advised if the patient is $>80$ years or $<60 \mathrm{~kg}{ }^{6}$

For patients $<60 \mathrm{~kg}$, a $50 \%$ reduction in dose is also recommended if they are again either $>80$ years or creatinine clearance $(\mathrm{CrCl})$ is $<30 \mathrm{~mL} / \mathrm{min}$.

Although there is no significant data available on dosing in mild hepatic impairment, apixaban should be avoided in patients with moderate-to-severe impairment.
Table 2 Pharmacokinetics of apixaban

\begin{tabular}{|c|c|}
\hline Mode of action & $\begin{array}{l}\text { Reversible and selectively inhibits free } \\
\text { and clot bound factor } \mathrm{Xa}\end{array}$ \\
\hline Prodrug & No \\
\hline Half-life & 12 hours \\
\hline Peak levels & I-2 hours \\
\hline Doses & $\mathrm{BD}$ \\
\hline Excretion & $25 \%$ renal \\
\hline $\begin{array}{l}\text { Use in pregnancy/ } \\
\text { breast feeding }\end{array}$ & No \\
\hline Interactions & $\begin{array}{l}\text { CYP3A4 and P-GP inducers: carbamazepine, } \\
\text { phenytoin and rifampicin - increases risk of } \\
\text { stroke/embolism } \\
\text { CYP3A4 and P-GP inhibitors: HIV protease } \\
\text { inhibitors, itraconazole, ketoconazole and } \\
\text { clarithromycin }\end{array}$ \\
\hline $\mathrm{CrCl} 15-29 \mathrm{~mL} / \mathrm{min}$ & $\begin{array}{l}\text { (+Age }>80 \text { OR weight }>60 \mathrm{~kg}) \text { reduced dose } \\
(50 \%)\end{array}$ \\
\hline $\mathrm{CrCl}<15 \mathrm{~mL} / \mathrm{min}$ & Not indicated \\
\hline Weight $<60 \mathrm{~kg}$ & $\begin{array}{l}(+\mathrm{Age}>80 \text { years or } \mathrm{CrCl} 15-29 \mathrm{~mL} / \mathrm{min}) \\
\text { reduced dose }(50 \%)\end{array}$ \\
\hline Mild hepatic impairment & Reduced dose \\
\hline $\begin{array}{l}\text { Moderate-to-severe } \\
\text { hepatic impairment }\end{array}$ & Not indicated \\
\hline
\end{tabular}

Abbreviations: $\mathrm{BD}$, twice daily; $\mathrm{CrCl}$, creatinine clearance; CYP3A4, cytochrome P450 3A4; HIV; human immunodeficiency virus; P-GP, P-glycoprotein.

The use of apixaban must be reviewed, however, in those patients taking cytochrome P4503 A4 (CYP3A4) and/or P-glycoprotein (P-GP) inducers (such as carbamazepine, 
phenytoin and rifampicin) as these medications may increase the risk of stroke and/or embolism. The opposite is consequently true for CYP3A4 and P-GP inhibitors, such as itraconazole, ketoconazole, clarithromycin and human immunodeficiency virus protease inhibitors, which may increase the risk of bleeding when used in conjunction with apixaban. ${ }^{7}$

The main RCTs defining the use of apixaban over warfarin have been the ARISTOTLE and AMPLIFY studies. ${ }^{4,5}$ ARISTOTLE reviewed the rates of stroke, death and bleeding during the use of apixaban (compared with warfarin) in AF-related stroke prevention. AMPLIFY randomized patients into receiving either conventional enoxaparin and warfarin or apixaban when diagnosed with acute VTE. The outcomes of these studies and drug safety profiles are discussed below.

\section{Efficacy in stroke prevention}

It is well known that the prevalence of AF increases with age, with $\sim 10 \%$ of the population over 80 years experiencing symptoms. ${ }^{8}$ The majority of these patients receive oral anticoagulant medication to reduce their risk of AF-related stroke. Previously prescribed medication has included warfarin or other VKAs, but their unpredictable coagulation profile and drug and food interactions limit their therapeutic use. ${ }^{9}$

With the advent of DOACs, multiple RCTs compared the use of warfarin with DOAC medications. The ARISTOTLE trial compared apixaban with warfarin in the management of AF-related stroke, particularly highlighting the rates of stroke, death and bleeding with both medications. ${ }^{5}$

For this study 18,201 patients were randomly assigned to either warfarin or $5 \mathrm{mg}$ BD apixaban therapy (2.5 mg BD for dose reduction). Although a small number of participants were lost to follow-up (2.1\%), overall results showed that fewer patients experienced symptoms of stroke or embolism on apixaban $(1.27 \%$ vs $1.60 \% ; P=0.01)$. There was a $49 \%$ relative risk reduction in the number of hemorrhagic stroke on apixaban (absolute risk reduction $[\mathrm{ARR}]=0.96 \%$, $P \leq 0.001$ ), and an $8 \%$ relative risk reduction in ischemic stroke $(P=0.42)$. Overall mortality rates were lower $(3.5 \%$ vs $3.9 \%, P=0.047$ ), and major bleeding was significantly lower at $2 \%$ with apixaban compared to just over $3 \%$ with warfarin (ARR $=1 \%, P<0.001) .{ }^{10}$

Alongside these results, apixaban has also been compared with aspirin therapy alone (AVERROES study). Results have again highlighted a $55 \%$ relative risk reduction $(\mathrm{ARR}=2.1 \%$, $P<0.001)$ in the rate of stroke or systemic embolism, with no increase in the risk of major bleeding $(P=0.07) .{ }^{11}$

\section{Efficacy in the prevention of VTE}

VTE is a significant issue in patients with reduced mobility, particularly after surgery. It is, therefore, important to ensure whether appropriate anticoagulant medication is prescribed to prevent venous thromboembolic disease. ${ }^{12}$

ADVANCE-1 and ADVANCE-2 trials were phase III clinical trials that evaluated the use of apixaban following total knee replacement. Both studies were noninferiority trials, where the ADVANCE-1 trial reviewed the use of apixaban $2.5 \mathrm{mg}$ once daily (OD) (1,599 patients) compared with subcutaneous enoxaparin $30 \mathrm{mg}$ BD (1,596 patients), and ADVANCE-2 randomized 1,528 patients to receive apixaban $2.5 \mathrm{mg} \mathrm{BD}$ and 1,529 patients to receive subcutaneous enoxaparin $40 \mathrm{mg}$ OD.

Results of both studies highlighted that apixaban was noninferior when compared with enoxaparin with regard to VTE prophylaxis $(\mathrm{ARR}=9 \%, P<0.0001)$, and showed a reduction in the rate of bleeding from $5 \%$ to $4 \%(P=0.09) .{ }^{13,14}$ Although no direct RCTs have been performed for the use of apixaban in the prevention of VTE outside hip and knee surgery, the data shown throughout this article are considered to be strong enough evidence for the use of apixaban for this purpose. ${ }^{13-15}$

\section{Efficacy in the treatment of VTE}

VTE has an annual incidence of 1-2 per million population and is commonly linked to immobility (e.g., surgery or flights $>4$ hours), coagulation disorders and the oral contraceptive pill. ${ }^{16}$ Conventional therapy includes initial treatment with enoxaparin and 3-6 months of warfarin therapy dependent on VTE anatomical location. The AMPLIFY study randomized and double blinded patients into conventional treatment or $10 \mathrm{mg}$ apixaban BD for 7 days followed by $5 \mathrm{mg}$ BD for 3 months. ${ }^{4}$

Five thousand and four hundred patients were enrolled in the study. Of these, a total of 130 patients experienced further thromboembolic events (2.3\% apixaban vs and 2.7\% conventional therapy), and a similar percentage in each cohort went on to have a positive diagnosis of PE. Overall bleeding rates were again significantly lower following the use of apixaban $(0.6 \%$ vs $1.8 \%)$, highlighting a clinically relevant overall relative risk reduction of $69 \%(\mathrm{ARR}=1.2 \%, P<0.001)$.

\section{Safety}

Both efficacy and safety are key aspects in the development of new medications. This review highlights the clinical results of apixaban; showing similar efficacy in the treatment of acute thromboembolism, AF-related stroke management and 
Table 3 Comparison of the major studies reviewed in the licensing of apixaban

\begin{tabular}{|c|c|c|c|c|c|}
\hline Study & Comparison & Apixaban dose & Outcomes & Bleeding events & Mortality \\
\hline ARISTOTLE 5 & $\begin{array}{l}\text { Apixaban vs warfarin for stroke } \\
\text { prevention in AF }(18,201 \\
\text { patients) }\end{array}$ & $5 \mathrm{mg} \mathrm{BD}$ & $\begin{array}{l}\text { Reduced rates of } \\
\text { stroke and/or embolism } \\
(\mathrm{RR}=0.79)\end{array}$ & $\begin{array}{l}\text { Reduced bleeding } \\
(\mathrm{RR}=0.67)\end{array}$ & $\begin{array}{l}\text { Reduced death } \\
\text { rates }(R R=0.89)\end{array}$ \\
\hline AMPLIFY $^{4}$ & $\begin{array}{l}\text { Apixaban vs enoxaparin followed } \\
\text { by warfarin for treatment of VTE } \\
\text { (5,400 patients) }\end{array}$ & $\begin{array}{l}10 \mathrm{mg} \text { OD for } 7 \text { days } \\
\text { followed by } 5 \mathrm{mg} \\
\text { for } 3 \text { months }\end{array}$ & Noninferior & $\begin{array}{l}\text { Reduced bleeding } \\
(\mathrm{RR}=0.33)\end{array}$ & N/A \\
\hline AVERROES"I & $\begin{array}{l}\text { Apixaban vs aspirin for stroke } \\
\text { prevention in AF ( } 5,599 \text { patients) }\end{array}$ & $5 \mathrm{mg} \mathrm{BD}$ & $\begin{array}{l}\text { Reduced rates of } \\
\text { stroke and embolism } \\
(\mathrm{RR}=0.43)\end{array}$ & Noninferior & $\begin{array}{l}\text { Reduction } \\
(\mathrm{RR}=0.80)\end{array}$ \\
\hline ADVANCE-I ${ }^{13}$ & $\begin{array}{l}\text { Apixaban vs enoxaparin for } \\
\text { VTE prophylaxis post total knee } \\
\text { replacement ( } 3,195 \text { patients) }\end{array}$ & $2.5 \mathrm{mg} \mathrm{BD}$ & Noninferior & Reduced & $\mathrm{N} / \mathrm{A}$ \\
\hline ADVANCE- $2^{14}$ & $\begin{array}{l}\text { Apixaban vs enoxaparin for } \\
\text { VTE prophylaxis post total knee } \\
\text { replacement ( } 3,057 \text { patients) }\end{array}$ & $2.5 \mathrm{mg} \mathrm{BD}$ & $\begin{array}{l}\text { Reduced rates of } \\
\text { VTE (RR 0.62) }\end{array}$ & Reduced & N/A \\
\hline
\end{tabular}

Abbreviations: AF, atrial fibrillation; $B D$, twice daily; OD, once daily; VTE, venous thromboembolism; RR, relative risk; N/A, not available.

VTE prophylaxis when compared with more conventional therapeutic techniques, but patient safety of any new medication is paramount.

The majority of the safety profiling for apixaban has been derived from the RCT's stated above, for example, ARISTOTLE and AMPLIFY. These studies have confirmed that the use of apixaban (when compared with warfarin) has a significantly lower rate of mortality, reduced incidence of major bleeding events (Table 3 ) and few recordable side effects. ${ }^{1}$

\section{Bleeding and bridging}

Reversal agents are currently being trialed, but the only marketed drug at present is idarucizumab (PRAXBIND) for dabigatran. ${ }^{17}$ Consequently, the same protocol as for major bleeding on warfarin must be adhered to: discontinue the drug, apply manual compression, maintain blood pressure, surgical/radiological intervention if appropriate and replace blood products $+/-$ prothrombin complex concentrate. ${ }^{18}$

To bridge a DOAC to enoxaparin, the DOAC should be discontinued and enoxaparin commenced at the same time as the next scheduled DOAC dose. When converting to warfarin, all DOACs should be discontinued when the patients' international normalized ratio is in the therapeutic range. For apixaban, therefore, the medication must be continued until recordable therapeutic levels of warfarin are reached (specific to indication), ensuring full anticoagulation effect.

\section{Conclusion}

The DOACs are quickly becoming the preferred treatment in the prevention and management of thromboembolic disease. Apixaban has been shown to be a safe alternative to other oral anticoagulant medications and has a reduced risk of bleeding and stroke when used for AF-related stroke prevention and fewer negative outcomes when used in VTE prophylaxis and treatment (Table 3 ). With a twice daily dosing regimen and no need for routine monitoring, apixaban is a safe and effective alternative to other oral anticoagulant medications.

\section{Disclosure}

The authors report no conflicts of interest in this work.

\section{References}

1. Halvorsen S, Atar D, Yang H, et al. Efficacy and safety of apixaban compared with warfarin according to age for stroke prevention in atrial fibrillation: observations from the ARISTOTLE trial. Eur Heart $J$. 2014;35(28):1864-1872.

2. Flaker G, Ezekowitz M, Yusuf S, et al. Efficacy and safety of dabigatran compared to warfarin in patients with paroxysmal, persistent, and permanent atrial fibrillation: results from the RE-LY (randomized evaluation of long-term anticoagulation therapy) study. $J \mathrm{Am}$ Coll Cardiol. 2012;59(9):854-855.

3. Halperin JL, Hankey GJ, Wojdyla DM, et al. Efficacy and safety of rivaroxaban compared with warfarin among elderly patients with nonvalvular atrial fibrillation in the rivaroxaban once daily, oral, direct factor Xa inhibition compared with vitamin $\mathrm{K}$ antagonism for prevention of stroke and embolism trial in atrial fibrillation (ROCKET AF). Circulation. 2014;130(2):138-146.

4. Agnelli G, Buller HR, Cohen A, et al; AMPLIFY Investigators. Oral apixaban for the treatment of acute venous thromboembolism. $N$ Engl JMed. 2013;369(9):799-808.

5. Al-Khatib SM, Thomas L, Wallentin L, et al. Outcomes of apixaban vs. warfarin by type and duration of atrial fibrillation: results from the ARISTOTLE trial. Eur Heart J. 2013;34(31):2464-2471.

6. Eikelboom JW, Connolly SJ, Gao P, et al. Stroke risk and efficacy of apixaban in atrial fibrillation patients with moderate chronic kidney disease. J Stroke Cerebrovasc Dis. 2012;21(6):429-435.

7. Hurst K, Lee R, Handa A. Quick reference guide to the new oral anticoagulants. J Vasc Surg. 2016;63(6):1653-1657.

8. Heeringa J, van der Kuip DA, Hofman A, et al. Prevalence, incidence and lifetime risk of atrial fibrillation: the Rotterdam study. Eur Heart J. 2006;27(8):949-953. 
9. Hart RG, Pearce LA, Aguilar MI. Meta-analysis: antithrombotic therapy to prevent stroke in patients who have nonvalvular atrial fibrillation. Ann Intern Med. 2007;146(12):857-867.

10. Hylek EM, Held C, Alexander JH, et al. Major bleeding in patients with atrial fibrillation receiving apixaban or warfarin: the ARISTOTLE trial (apixaban for reduction in stroke and other thromboembolic events in atrial fibrillation): predictors, characteristics, and clinical outcomes. J Am Coll Cardiol. 2014;63(20):2141-2147.

11. Connolly SJ, Eikelboom J, Joyner C, et al. Apixaban in patients with atrial fibrillation. $N$ Engl J Med. 2011;364(9):806-817.

12. NICE [webpage on the Internet]. Venous thromboembolism in adults: reducing the risk in hospital. 2010. Available from https://www.nice. org.uk/guidance/qs3. Accessed June 13, 2017.

13. Lassen MR, Gallus A, Raskob GE, et al. Apixaban versus enoxaparin for thromboprophylaxis after hip replacement. $N$ Engl J Med. 2010;363(26):2487-2498.

14. Lassen MR, Raskob GE, Gallus A, Pineo G, Chen D, Hornick P; ADVANCE-2 investigators. Apixaban versus enoxaparin for thromboprophylaxis after knee replacement (ADVANCE-2): a randomised double-blind trial. Lancet. 2010;375(9717):807-815.

15. Mandernach MW, Beyth RJ, Rajasekhar A. Apixaban for the prophylaxis and treatment of deep vein thrombosis and pulmonary embolism: an evidence-based review. Ther Clin Risk Manag. 2015;11:1273-1282.

16. Goldhaber SZ, Bounameaux H. Pulmonary embolism and deep vein thrombosis. Lancet. 2012;379(9828):1835-1846.
17. Idarucizumab (praxbind) - an antidote for dabigatran. Med Lett Drugs Ther. 2015;57(1482):157-158.

18. Keeling D, Cotter F. Management of bleeding in patients taking FXa and FIIa inhibitors. Br J Haematol. 2013;160(1):1-2.

19. Bauersachs R, Berkowitz SD, Brenner B, et al. Oral rivaroxaban for symptomatic venous thromboembolism. N Engl J Med. 2010;363(26): 2499-2510.

20. Büller HR, Prins MH, Lensin AW, et al; EINSTEIN-PE Investigators. Oral rivaroxaban for the treatment of symptomatic pulmonary embolism. N Engl J Med. 2012;366(14):1287-1297.

21. Piccini JP, Hellkamp AS, Lokhnygina Y, et al. Relationship between time in therapeutic range and comparative treatment effect of rivaroxaban and warfarin: results from the ROCKET AF trial. J Am Heart Assoc. 2014;3(2):e000521.

22. Schulman S, Kearon C, Kakkar AK, et al; RE-COVER Study Group. Dabigatran versus warfarin in the treatment of acute venous thromboembolism. N Engl J Med. 2009;361(24):2342-2352.

23. Ruff CT, Giugliano RP, Antman EM, et al. Evaluation of the novel factor Xa inhibitor edoxaban compared with warfarin in patients with atrial fibrillation: design and rationale for the effective aNticoaGulation with factor $\mathrm{xA}$ next generation in atrial fibrillation-thrombolysis in myocardial infarction study 48 (ENGAGE AF-TIMI 48). Am Heart J. 2010;160(4):635-641.

24. Said K. Hokusai-VTE: edoxaban for the treatment of venous thromboembolism. Glob Cardiol Sci Pract. 2013;2013(4):416-420.
Vascular Health and Risk Management

\section{Publish your work in this journal}

Vascular Health and Risk Management is an international, peerreviewed journal of therapeutics and risk management, focusing on concise rapid reporting of clinical studies on the processes involved in the maintenance of vascular health; the monitoring, prevention and treatment of vascular disease and its sequelae; and the involvement of

\section{Dovepress}

metabolic disorders, particularly diabetes. This journal is indexed on PubMed Central and MedLine. The manuscript management system is completely online and includes a very quick and fair peer-review system, which is all easy to use. Visit http://www.dovepress.com/ testimonials.php to read real quotes from published authors. 